\title{
The Reproductive Effect of Terbinafine in Ewe: Effects on Estrous Cycle and Ovarian Follicles
}

\author{
Muhannad A. A. AlBayaty ${ }^{*}$, Eman Rasol AIShaty ${ }^{*}$ and Alaa Karim Jassim ** \\ * Department of Physiology and pharmacology, College of Veterinary Medicine, University of Baghdad, \\ *** Ministry of Higher Education and Scientific Research, Research and development
}

\section{Summary}

Terbinafine is a fungicide given orally with the dose of $100 \mathrm{mg} / \mathrm{kg}$ body weight per day for each ewe for 60 days. The vaginal smears of ewe, body and ovarian weight were daily administered at slaughter time; ewes were slaughtered at $60^{\text {th }}$ day. Estrous cycle was affected by showing a significant reduce in the estrous cycle length of each phases of estrous cycle with associated significant increase in the diestrus phase in terbinafine treatment as compared with control group (olive oil treatment as adjuvant) of ewes. There was a significant reduce in the number of follicles and a significant raise in the number of atretic follicles in treated group as compared with control group as well as upsurge the progesterone/estrogen ratio. The body and ovarian weight were significant diminished in terbinafine treatment. These observed effects of terbinafine on the ovarian activity may be due to a direct effect as antiproliferative agent or the hypothalamus - hypophysial - ovarian axis causing hormonal inequality.

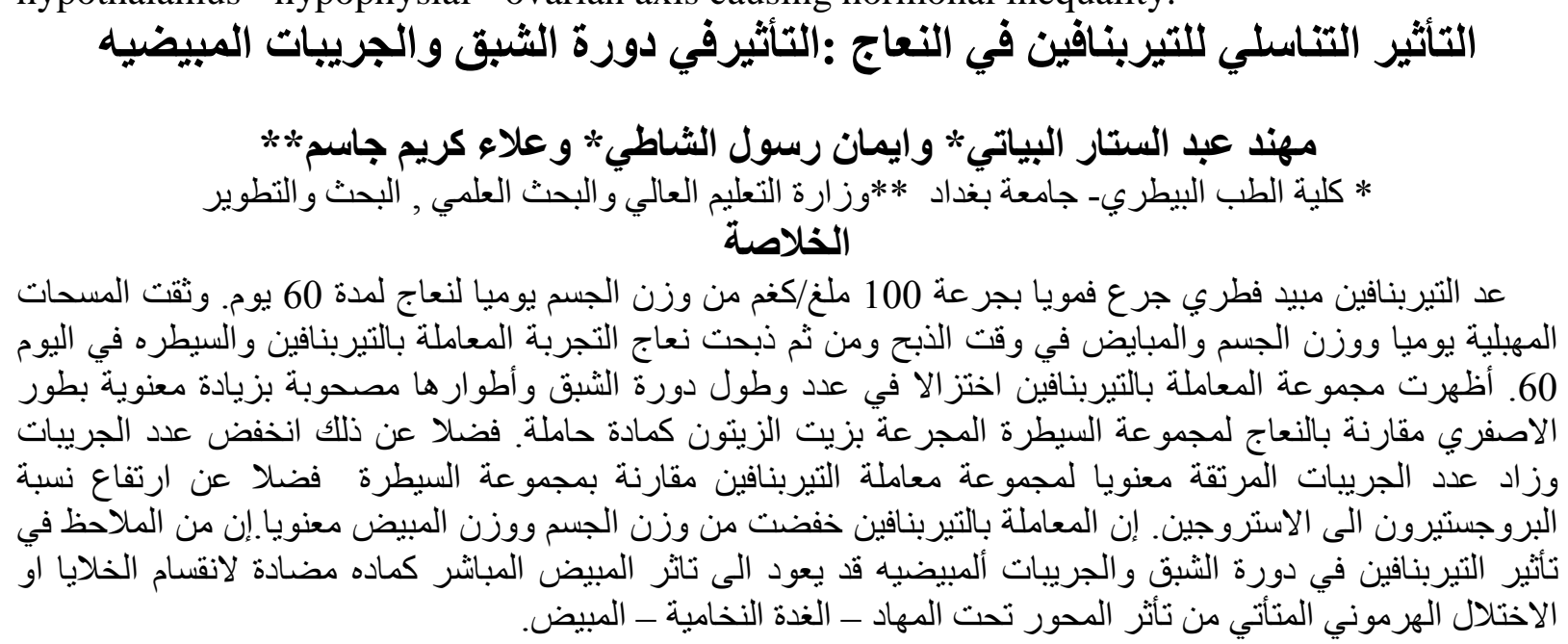

\section{Introduction}

Antifungal vary from any other chemical substances because they are knowingly used for long duration, therefore, a great part of the living animal population might be exposed in either the abuse or accidentally treatment, in other wise several attempting to use a new generation of antifungal to avoid resistance and adverse effects. The use of antifungal, takes place mostly through topical or systemic route (1 and 2$)$. The really exposure determines the detrimental consequence that this exposure could had deleterious effects on reproductive performance. In animals, if primordial follicles are shattered widely, they could not be renewed; which can cause premature ovarian failure and early aged (3).

The terbinafine $\mathrm{HCl}$ (allylamine derivative) displayed in figure 1, which has a broadspectrum antifungal activity, is a synthetic form, which exerts its' antifungal effect by inhibiting squalling epoxidase, a key enzyme in sterol biosynthesis in fungi further terbinafine inhibits the production of ergosterol in such a way as to lead to the buildup of the ergosterol precursor known as squalene. Having the wrong structural components disrupts the function of the cell wall as a barrier. This action results in a deficiency in ergosterol and a corresponding accumulation of sequalene within the fungal cell and causes fungal cell bereavement ( 4 and 5). It is chiefly used against most strain of the following organism dermatophyte mycetoma, ringworm and in particular, Aspergillus species (6). Yeganeh and McLachlan (7) reported that the terbinafine dwindled sexual function and ended testicular risk in rats (8). 


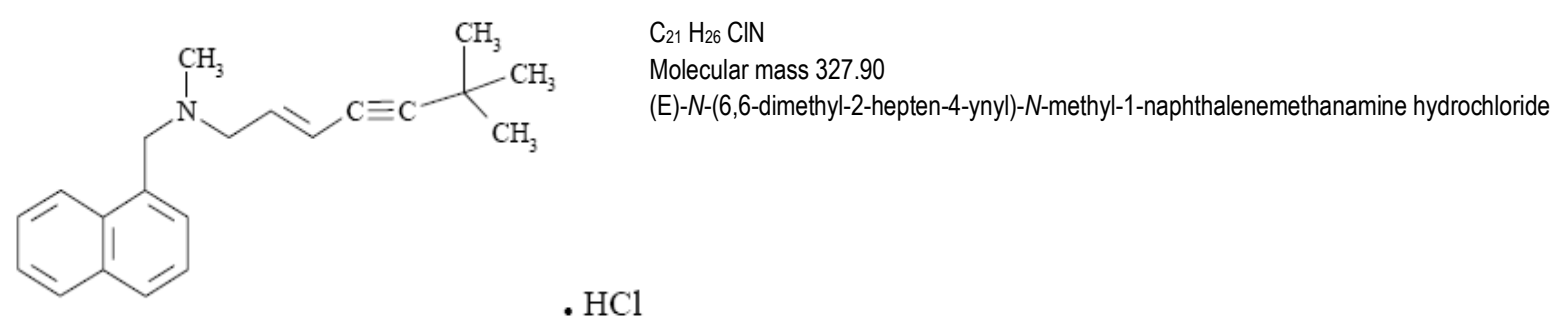

Figure 1: The molecular structure of terbinafine (4).

The terbinafine fungicide also has been lately report in the initiation of steroidal hormone disruption to woman-dosed contraceptive after chronic exposure to terbinafine and interacting with contraceptive $(9,10$ and 11). In view of the above findings, the present study had been undertaken to be acquainted with the effect of a terbinafine fungicide, on estrous cycle and folliculogenesis in ewe.

\section{Materials and Methods}

Terbinafine sample was purchased from Dr. Reddy's Laboratories (UK) Ltd, 6 Riverview Road, Beverley, HU17 OLD, UK, Terbinafine dissolved in olive oil as a vehicle for oral administration. Twenty ewes aged one year (Local bread), weighing between $30-40 \mathrm{~kg}$, screening regular estrous cycle, which were divided in to two equal groups (control and terbinafine treated group). Ewes groups were housed in to semi-closed arena (private Ownership: AlWahda) and had free access to concentrate pellets diet and water ad libitum all through the experiment. The lighting schedule was $\sim 12: 12 \mathrm{~h}$ light and dark cycle, the protocol of experimental design done at $10^{\text {th }}$ December to $20^{\text {th }}$ February. Terbinafine treated ewes group dosed $100 \mathrm{mg} / \mathrm{kg}$ per day orally for 60 days. The control group received an equal volume of olive oil. Vaginal smear and body weight recorded daily during the study.

The phases of estrous cycle were determined by observing the vaginal smear in the morning (10 to 11 hour). Expermental ewes in both control and terbinafine treated group were slaughtered at end $60^{\text {th }}$ days of experiment time (12).

Diestrous index was obtained after loading terbinafine duration of treatment as a relationship between diestrous period to treatment period (13), which calculated as follows:

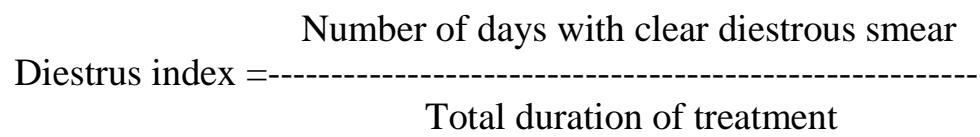

Blood samples were collected at $60^{\text {th }}$ on the day of estrous phase. Samples were immediately placed on ice and centrifuged within $1 \mathrm{~h}$. Plasma was recovered and stored frozen until analyzed by radioimmunoassay (Baghdad hospital Lab.) for both estrogen and progesterone.

Morphometric analysis of follicular development :- Ovaries of five animals randomly selected in both groups were taken for follicular development studies. The estrous cycle phases of the five examined ovaries exhibited were in diestrus phase. The weight of ovaries of the ewes nearest to the mean weight of the ovaries of respective group was selected. The ovaries were put in Bouin's fixative fluid, sectioned at 5- $\mu \mathrm{m}$ thickness, and stained with hematoxylin and eosin. Every one of successive sections of the ovary was counted for assorted stages of development of follicles as describe by (14). Follicles were classified according to $(14,15$ and 19) into small, medium, and large follicles. Healthy and atretic follicles were classified as defined by (16). In this study, three classes of ovarian follicles were categorized using the comparative cross sectional diameter of the follicle as measured from the outer margins of the granulosa cell layers. These quantitative criteria represent a substantial generalization of an 
elaborated grading system proposed by Pedersen and Peters (14) and Lundy, et al. (15), with eight stages and several sub-stages to differentiate between primordial oocytes (Type 1) to antral follicle (Type 8).

1. Small follicles-(Pedersen and Peters Types 1-3b) consisted of an isolated oocyte or an oocyte surrounded by a partial or unbroken layer of granulosa cells.

2. Medium/growing follicles-(Pedersen and Peters Types 4-5b) have an oocyte surrounded by multilayered, solid mantle of granulosa cells.

3. Large/antral follicles-(Pedersen and Peters Types 6- 8) were characterized by central oocyte and fluid filled space bordered by number of granulosa cells.

By using these principles, mean diameters of follicles have been measured at approximately $<20 \mu \mathrm{m}$ for small, $20-70 \mu \mathrm{m}$ for medium and $>70 \mu \mathrm{m}$ for large follicles in mice. Follicles showing the nucleus of the oocyte were measured by using a calibrated ocular micrometer to avoid repeated counting. The maximum diameter and diameter at the right angle to it were used to find a mean diameter for each follicle. A follicle was considered to be undergoing atresia or to regressing when two or more pyknotic granulose cells would be establish in a single section or whether the oocyte showed signs of degeneration, such as fragmentation, loss of nuclear membrane, or thinning of cumulus oophorus as proposed by (17).

Body and organs weight

The body weight was intended based on the weight taken on the $1^{\text {st }}$ day following the oral administration measured as the initial body weight and the weight taken on the end day of experiment before slaughter was measured as the final weight. Ovary, was dissected, freed from adherent tissue and weighed. Ovaries weights were expressed per body weight.

Statistics

Statistical analysis of the control and terbinafine treated group data were subjected to analysis of variance (ANOVA) one-way analysis. A probability of $\mathrm{p}<0.05$ was assumed to denote a significant difference. LSD test was used for group comparison.

\section{Estrous cycle studies}

\section{Results}

The control group showed signs of ordinary estrous cycle and usual period of each phases of estrous cycle. Treatment with $100 \mathrm{mg} / \mathrm{kg}$ per day terbinafine caused a significant $(\mathrm{p}<0.05)$ delayed in the length of estrous cycle and period of proestrus, estrus and metestrus with associated significant $(\mathrm{p}<0.05)$ amplify in the period of diestrus phase.

Diestrus index was also exaggerated the index following the oral administration of terbinafine (Table 1). However, the treated ewes were depressed and display lost of their normal activity.

Table (1) the effect of terbinafine on the estrous cycle phase

\begin{tabular}{|c|c|c|c|c|c|c|}
\hline \multirow[b]{2}{*}{ Groups } & \multirow{2}{*}{$\begin{array}{c}\text { Total } \\
\text { estrous cycle } \\
\text { length (days) }\end{array}$} & \multicolumn{4}{|c|}{ Estrous cycle period } & \multirow[b]{2}{*}{$\begin{array}{c}\text { Diestrus } \\
\text { index }\end{array}$} \\
\hline & & $\begin{array}{l}\text { Proestrus } \\
\%\end{array}$ & Estrus \% & Metestrus \% & Diestrus \% & \\
\hline Control & $21.39 \pm 2.80$ a & $\begin{array}{l}15.36 \pm 3.07 \\
\text { a }\end{array}$ & $18.55 \pm 1.72$ a & $22.14 \pm 2.60$ a & $\begin{array}{l}43.93 \pm 2.13 \\
\text { a }\end{array}$ & 42.16 \\
\hline $\begin{array}{l}\text { Terbinafine } \\
\text { treatment }\end{array}$ & $\begin{array}{r}25.51 \pm \\
3.33 \text { b }\end{array}$ & $\begin{array}{l}\text { 7.07士 } \\
0.074 \text { b }\end{array}$ & $\begin{array}{l}10.55 \pm \\
0.019 \text { b }\end{array}$ & $\begin{array}{l}22.49 \pm \\
0.063 \text { a }\end{array}$ & $\begin{array}{l}59.87 \pm \\
0.308 \text { b }\end{array}$ & 74.39 \\
\hline
\end{tabular}

$\mathbf{N}=20$ ewe

Values presented as mean \pm standard error

Letters: $(P<0.05)$ vs. differences between treatment and control group.

\section{Morphometric analysis of follicular growth studies}

The histologic pattern of the control ewe group exhibited number of different developing follicles, Graafian follicles, atretic follicles and Corpora lutea. Treatment with $100 \mathrm{mg} / \mathrm{kg}$ per 
day terbinafine showed a significant $(\mathrm{p}<0.05)$ reduce in the number of healthy follicles with concomitant significant $(\mathrm{p}<0.05)$ increase in the number of atretic follicles (Tables 2 and 3 ) when compared with the control group of ewes.

Table (2) effect of terbinafine on ovarian follicular numbers

\begin{tabular}{|c|c|c|c|c|}
\hline \multirow[b]{2}{*}{ Groups } & \multicolumn{3}{|c|}{$\begin{array}{c}\text { Number of follicles according to size classification } \\
\text { (diameter) }\end{array}$} & \multirow{2}{*}{$\begin{array}{l}\text { Total number of } \\
\text { follicles }\end{array}$} \\
\hline & Small $<20 \mu \mathrm{m}$ & $\underset{\mu \mathrm{m}}{\operatorname{Medium} 20-70}$ & Large $>70 \mu \mathrm{m}$ & \\
\hline Control & $26.5 \pm 5.42$ a & $4.29 \pm 0.37 a$ & $0.88 \pm 0.06$ a & $31.67 \pm 0.21 a$ \\
\hline $\begin{array}{c}\text { Terbinafine } \\
\text { treatment }\end{array}$ & $17.5 \pm 1.38 \mathrm{~b}$ & $2.86 \pm 0.24 b$ & $0.42 \pm 0.03 \mathrm{~b}$ & $20.78 \pm 0.55 b$ \\
\hline
\end{tabular}

$\mathbf{N}=\mathbf{2 0}$

Values presented as mean \pm standard error.

Letters: $(P<0.05)$ vs. differences between treatment and control group.

Table (3) effect of terbinafine on ovarian atretic follicles number

\begin{tabular}{|c|c|c|c|}
\hline \multirow[b]{2}{*}{ Groups } & \multicolumn{2}{|c|}{$\begin{array}{l}\text { percentage of atretic follicles according to size } \\
\text { classification (diameter) }\end{array}$} & \multirow{2}{*}{$\begin{array}{l}\text { Total number } \\
\text { of atretic } \\
\text { follicles }\end{array}$} \\
\hline & Medium 20 - $70 \mu \mathrm{m}$ & Large $>70 \mu \mathrm{m}$ & \\
\hline Control & $58.4 \pm 2.61 \mathrm{a}$ & $94.72 \pm 3.28 \mathrm{a}$ & $3.01 \pm 1.12 \mathrm{a}$ \\
\hline $\begin{array}{l}\text { Terbinafine } \\
\text { treatment }\end{array}$ & $55.81 \pm 1.99 \mathrm{~b}$ & $98.24 \pm 6.45 \mathrm{~b}$ & $2.51 \pm 1.31 \mathrm{~b}$ \\
\hline
\end{tabular}

$\mathbf{N}=\mathbf{2 0}$

Values presented as mean \pm standard error

Letters: $(P<0.05)$ vs. differences between treatment and control group

\section{Estrogen/progesterone ratio:}

The figure 2 showed significant $(\mathrm{p}<0.05)$ increase in progesterone to estrogen ratio in terpenafine treated group $29.73 \pm 1.51$ as compared control group $24.44 \pm 0.46$.

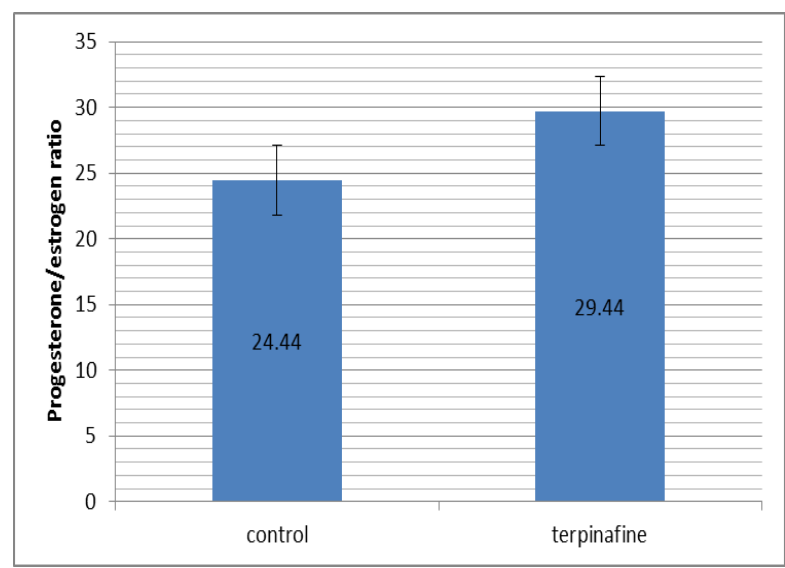

Figure 2: The effect of terbinafine treatment on progesterone/estrogen ratio in control and terbinafine treated groups.

\section{$\mathbf{N}=\mathbf{2 0}$}

Values presented as mean \pm standard error

Letters: $(P<0.05)$ vs. differences between treatment and control group

Body and organs weight 
The ewe treated with terbinafine for 60 days showed a significant $(\mathrm{p}<0.05)$ decrease in the gain of body weight with terbinafine treatment. There was a significant decrease in the weight of the ovary (Table 4). ratio

Table (4) effect of terbinafine on body weight and ovarian weigh to body weight

\begin{tabular}{|l|l|l|l|}
\hline Groups & $\begin{array}{l}\text { Body weight } \\
\text { kg }\end{array}$ & \multicolumn{1}{c|}{$\begin{array}{c}\text { Ovarian } \\
\text { weight g }\end{array}$} & $\begin{array}{c}\text { Ovarian } \\
\text { weight to body } \\
\text { weight ratio \% }\end{array}$ \\
\hline \multicolumn{1}{|c|}{ Control } & $\mathbf{3 5 . 6 2} \pm \mathbf{0 . 5 4}$ a & $\mathbf{3 7 . 2 1} \pm \mathbf{0 . 0 1 9}$ a & $\mathbf{0 . 1 0 4} \pm \mathbf{0 . 0 3 1}$ a \\
\hline $\begin{array}{l}\text { Treatment } \\
\text { terbinafine }\end{array}$ & $\mathbf{3 0 . 8 4} \pm \mathbf{0 . 9 5} \mathrm{b}$ & $\mathbf{2 8 . 1 4} \pm \mathbf{0 . 0 2 6} \mathbf{b}$ & $\mathbf{0 . 0 9 1} \pm \mathbf{0 . 0 6 9}$ b \\
\hline
\end{tabular}

$\mathbf{N}=\mathbf{2 0}$

Values presented as mean \pm standard error

Letters: $(P<0.05)$ vs. differences between treatment and control group

\section{Discussion}

Cyclic transforms of the vaginal smear see in the estrous cycle offers a sensible index of the ovarian vital activity and its hormonal biosynthesis of estrogen, progesterone, and prostaglandins, the echelons of these hormones are controlled by hypothalamus gonadotropin releasing hormone and pituitary gonadotropin (18). The consequences obtained in the present study indicate that the control ewe exhibited regular $\sim 21.39$ days estrous cycle. Ewes treated with $100 \mathrm{mg} / \mathrm{kg}$ per day terbinafine produces diminishes in the estrous cycle length and the period of proestrus and estrus with attendant significant amplify in diestrus phases. However, diestrus index was expansion following the treatment of terbinafine as compared with control group.

Comparable outcomes have been indication that the rat extravagances with an allylamine fungicide reason a significant increase in the estrous cycle period associated with of the proestrus, estrus, and metestrus period with a concomitant increase in diestrus phase (11). As if outcomes have also been reports with steroidal hormone interaction, in controversy, demonstrated an ability to persuade the fast migration estrus phase, thus affecting the number sequence of estrous cycle resultant from the hormonal disparity and reduced estrus phase (20). In experiment, it has been revealed that treatment with terbinafine displayed extended diestrus phase and therefore, terbinafine perhaps have interacted with steroidal metabolism and it has been demonstrated in the liver cytochrome inhibitor compounds treated animals. It has been reported that at least seven cytochrome $\mathrm{P} 450$ isoenzymes are involved in its metabolism with major contributions from CYP 2C9, CYP 1A2, CYP 3A4, CYP 2C8 and CYP 2C19. Terbinafine down regulated these CYPs, steroidal hormones, on the other hand, is metabolized associated CYPs of terbinafine (21).

Several possibilities may explain the pharmacological interactions with estrogen. Since terbinafine's protein binding (99\%) is stronger than that of steroidal hormones (40-60\%), terbinafine might have displaced sexual steroidal hormones from the protein binding sites, increasing its serum level and causing disrupting cyclicity rhythms and period and disturbance of mechanism. It is also possible that terbinafine would have displaced bupropion and/or quetiapine from their binding sites, increasing their levels and causing the described side effects. However, the presence of high estrogenic serum level, with the onset of symptoms, and normalization of its serum level, with the resolution of symptoms, suggests a probable cause (22).

Further, terbinafine and steroid hormone share the metabolic pathway at CYP3A4, CYP450 3A4, isoenzymes. It is possible that terbinafine displaced the steroid at these isoenzyme sites (27), leading to its own metabolism. Further, steroid's potent induction at CYP $3 \mathrm{~A} 4,1 \mathrm{~A} 2$ could also have caused the metabolism and excretion of terbinafine, while estrogen levels continued to increase. The half-life of estrogen, in most cases, is $\sim 13$ hours. However, in 


\section{Proceeding of the Eleventh Veterinary Scientific Conference, 2012; 225-231}

the above case, steroid levels were detectable after 10 days of stopping medications (11 and 20). The long terminal down regulation of metabolic enzyme of terbinafine might explain this.

Tebinafine may be revealed to block the ovulation via restrain the pustule secretion of $\mathrm{LH}$ as sequence of sexual hormone disruption (23). Since terbinafine may be probable that it would deleterious effect indirectly on the hypothalamus - pituitary axis with adversely side effects (20), affect the ovary, which in turn affects the estrous cycle and folliculogenesis due to the hormonal imbalance in estrogen - progesterone ratio. That coincided with hormonal result displayed in figure 1 showed comparable between progesterone/estrogen ratio the ewes in terpinafine treated group complain from rising their ratio as compared with control.

Plowchalk, (24) have descripted that the quantitative appraisal of follicle number is a marker of the usual function in addition to noxious replies in the ovary. Follicles are the principle functional units of the mammalian ovary. The majority vital directors of follicular maturity are follicular stimulating hormone (FSH), Luteinizing hormone (LH) created from the pituitary gland, and the ovarian estrogen formed through granulosa cells. Although all follicles are in fact exposed to the equivalent frequencies in these hormones, several ovulated follicles, and others become atretic, indicating the attendance of intra-gonadal regulatory factors and steroidogenesis with steroidal hormone turnover, which adapt the outcome of these major hormones (25). In this experiment revealed that the number of vary sized follicles and total numbers of healthy follicles were drastically reduced with attendant significant augment in medium, large and total number of atretic follicles in terbinafine treated group of ewes.

On the other hand, recently, we have shown that a number of antifungal agents exert antiproliferative and/or apoptotic activities in various malignant cells in vitro and in vivo. For instance, our previous studies showed that terbinafine; (allylamines class) induced cell cycle arrest at the G0/G1 phase of the cell cycle and the occurrence of apoptosis cells, which highlight the molecular mechanisms of TB-induced antitumoral activity (26). In the present study, the antiproliferative activity of terbinafine may be presumably referred to bad sequence of folliclogenesis and reduced their numbers.

Treatment with terbinafine showed adverse effect in terms of body weight which significant decrease in the body weight in terbinafine treated group, as there may be suppression food and water intake due to anorexia (28); this may presumably one of the motives for low body weight and alteration in the estrous cycle. The ovarian weight was decreased with terbinafine treatment. Similar observations were ended in rats complain from malnutrition that produced decrease in ovaries weight and size due to widespread atretic follicles (29).

Poly-pharmacy carries an inherent risk that needs to be assessed before animal are prescribed multiple medications. In addition, this case may represent an interaction due to abused drug, which may not apply to the majority of the animal for a long time course. However, this report suggests that a probable relationship exists between terbinafine and physiology of estrous cycle which where violates the safeness information through literature notions. Until further research is available, care should be exercised whenever they are prescribed for certain period margin safety.

\section{References}

1. Hoyer, P. and Sipes, I. (1996) Assessment of follicle destruction in chemical-induced ovarian toxicity,Ann. Rev. Pharmacol. Toxicol. 36:307-31.

2. Larson, JL.; Thomas, L.; Wallace Rochelle, WT.; Melissa CM.; Christina BM., and Paul, AC. (2000). The reproductive and developmental toxicity of the antifungal drug nyotran t (liposomal nystatin) in rats and rabbit. Tox. Sci., 53: 421-429.

3. Hirshfield, AN. (1991). Development of follicles in the mammalian ovary. Int. Rev. Cytol., 124: 43-100.

4. Palomaki, A. C. (2010) Toxicity and Mode of Action of the Pharmaceutical Fungicides Fluconazole and Terbinafine to Freshwater Algae. Department of Chemical and Biological Engineering Chalmers University of Technology Göteborg, Sweden. 


\section{Proceeding of the Eleventh Veterinary Scientific Conference, 2012; 225-231}

5. Ryder, N.S. (1992). Terbinafine: Mode of action and properties of the squalene epoxidase inhibition. British Journal of Dermatology. 126, Supplement 39, 2-7.

6. Nuttall, T.J., German, A.J., Holden, S.L., Hopkinson, C., and McEwan, N.A. (2008) Successful resolution of dermatophyte mycetoma following terbinafine treatment in two cats. Vet. Dermatology 19: 405-410

7. Yeganeh, MH. and McLachlan, AJ. (2002) Physiologically Based Pharmacokinetic Model for Terbinafine in Rats and Humans Antimicrob Agents Chemother. 46(7): 2219-2228.

8. Nejjam, F., Zagula, M., Cabiac, M.D., Guessous, N., Humbert, H., Lakhdar, H. (1995) Pilot study of terbinafine in children suffering from tinea capitis: evaluation of efficacy, safety and pharmacokinetics. Br. J. Dermatol. 132(1):98-105.

9. Medwatch. (2001).Summary Of Safety-Related Drug Labeling Changes Approved by FDA Center for Drug Evaluation and Research (CDER) Washington, DC, USA: Food and Drug Administration;

10.Shear, N., Drake, L., Gupta, A.K., Lambert, J., Yaniv, R. (2000) The implications and management of drug interactions with itraconazole, fluconazole and terbinafine. Dermatology; 201(3):196-203.

11.Elewski, B and Tavakkol, A. (2005) Safety and tolerability of oral antifungal agents in the treatment of fungal nail disease: a proven reality Ther Clin Risk Manag. 1(4): 299-306.

12.Al-Wahab, R.M. and Khudyer, A.N. (1981). Determination of puberty and reproductive capacity in Awassi ewe lambs treated with progesterone. World Rev.Anim.Prod.17:31-40.

13.Cooper, RL, Goldman, JM, Vandenbergh, JG (1993) Monitoring of the estrous cycle in the laboratory rodentby vaginal lavage. In: Methods in toxicology female reproductive toxicology, eds. by Heindel J.J., Chapin R.E. Vol. 3 B, 57-8, Academic Press, San Diego.

14.Lundy, T., Smith, P.; O'Connell, A.; Hudson, N. L. and McNatty, K. P. (1999). Populations of granulose cells in small follicles of the sheep ovary. Journal of reproductive fertility, 115, 251-262.

15.Pedersen, T. and Peters, H. (1968) Proposal for a classification of oocytes and follicles in the mouse ovary. Journal of reproductive fertility, 17, 555-557.

16.Swartz WJ, Mall GM (1989) Chlordecone induced follicular toxicity in mouse ovaries. Reprod. Toxicol. 3, 203-9.

17.Osman, P. (1985) Rate and course of atrasia during follicular development in the adult cycle rat, J. Reprod. Fert. 73, 261-70.

18.Larson, G., Lewis, P., Dailey, R. A., Inskeep, E. and Townsend. E. (1987) Follicle stimulating hormone pattern and function in ewes receiving bovine follicular fluid during three stages of the estrous cycle, $\mathrm{J}$. Ani. Sci., 64:1491-1497.

19.Myers, M.; Britt, KL.; Wreford, M.; Ebling, FJ. and Kerr, JB. (2004) Methods for quantifying follicular numbers within the mouse ovary, Reproduction 127 569-580.

20.Navdeep, S. B., Jennifer and H., Pirzada, S. (2006) Possible Carbamazypine Toxicity with Terbinafine, Can. J. Clin. Pharmacol. 13 (2): 228-231.

21. http: // www. rxmed. com / b. main / b2. pharmaceutical / b2. 1. monographs / CPS - \%20 monographs / CPS - \%20 (General \%20 Monographs - \% 20L) / LAMISIL. html (Last accessed on 8-03-2005).

22. http://www.rxlist.com/cgi/generic/terbin_cp.htm (Last accessed 8-03-2005).

23. Jablonka-Shariff, A., Fricke, P., Grazul-Bilska, A., Reynolds, L. and Redmer, D.,(1994) Size, Number, Cellular Proliferation, and Atresia of Gonadotropin-Induced Follicles in Ewes, Biology of Reproduction, 51, 531-540.

24. Plowchalk DR, Smith BJ, Mattison DR (1993) Assessment of toxicity to the ovary using follicle quantiation and morphometrics. In: Methods in toxicology: female reproductive toxicology, eds.by Heindel JJ, Chapin RE, Vol.3 B, 57-8, Academic Press, San Diego.

25. Asmathabanu I, Kaliwal BB (1997) Temporal effect of methyl parathion on ovarian compensatory hypertrophy, follicular dynamics and estrous cycle in hemicastrated albino rats. Basic and Clinical Physiol and Pharmacol 8, 237-54.

26. Wen-Sen Lee1, Rong-Jane Chen, Ying-Jan Wang, How Tseng1, Jiiang-Huei Jeng, Shyr-Yi Lin, YuChih Liang, Chien-Ho Chen, Chien-Huang Lin, Jen-Kun Lin, Pei-Yin Ho, Jan-Show Chu, Wei-Lu Ho, Li-Ching Chen, Yuan-Soon Ho (2003) In vitro and in vivo studies of the anticancer action of terbinafine in human cancer cell lines: G0/G1 p53-associated cell cycle arrest. Inter. J. of Cancer,106(1): 125-137

27. Frances, A. K, and Willam Hansel (1974) Estrogen Cytosol Binding Proteins in Bovine Endometrium and Corpus Luteum1 BIOLOGY OF REPRODUCTION 11, 566-577.

28. Chang, G C. and Schiano T. D. (2007) Review article: drug hepatotoxicity. Aliment. Pharmacol. Ther. $25,1135-1151$.

29. Hafez, B. and Hafez, E. (2000) reproduction in farm animals $7^{\text {th }}$ ed. Lippincott William and Wilkins, Tokyo. 